Original Contribution

\title{
SURVIVAL IN PATIENTS OPERATED ON DUE TO PULMONARY METASTASES FROM COLORECTAL CARCINOMA
}

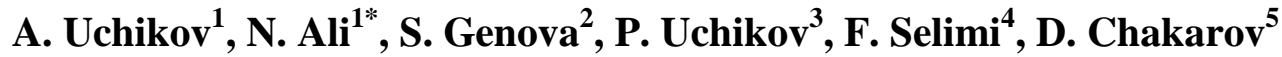 \\ ${ }^{1}$ Department of Special Surgery and Second Surgical Clinic, University Hospital "St. George", \\ MU-Plovdiv, Bulgaria \\ ${ }^{2}$ Department of General and Clinical Pathology, MU-Plovdiv, Bulgaria \\ ${ }^{3}$ MU-Plovdiv, Bulgaria \\ ${ }^{4}$ Department of Visceral Surgery, Clinical Hospital-Tetovo, Republic of Macedonia, \\ ${ }^{5}$ Department of Propedeutics of Surgical Diseases, MU-Plovdiv, Bulgaria
}

\begin{abstract}
Introduction: Colorectal cancer $(\mathrm{CRC})$ is one of the most common cancers worldwide, with greater than 1 million cases identified in the world yearly. It has got a high metastatic potential and lungs are the second most common site. Although it is referred to as a systemic disease complete surgical resection of pulmonary metastases can enhance survival in selected patients. Patients and methods: The study focuses on a sample of 13 patients surgically treated on the occasion of lung metastases from CRC; Results: We found that the mean survival in patients operated on due to pulmonary metastases from CRC was 57,1 months (95\% CI; 35,400-78,907). Conclusion: Pulmonary resection of metastatic colorectal carcinoma is safe and results in longterm survival. Low morbidity and mortality rates, contrasting with lack of any other effective therapy, justify aggressive surgical management.
\end{abstract}

Key words: colorectal carcinoma, pulmonary metastases, surgery, survival

\section{INTRODUCTION}

Colorectal cancer is the third most common cancer in men $(746,000$ cases, $10.0 \%$ of the total) and the second in women $(614,000$ cases, $9.2 \%$ of the total) worldwide (1). In the Republic of Bulgaria the total registered cases of colorectal carcinoma for 2014 were 31,284, with 1,289 cases more than those registered in 2012. In 2014 the total registered patients with CRC in Sofia were 5,832, in Plovdiv3,215 and 1,597 cases in Stara Zagora $(2,3)$. Colon cancer is a systemic disease in $19 \%$ of patients and can metastasize to the liver, lung, ovary, peritoneum and other organs systemically. Approximately $20 \%$ of patients with CRC have distant metastasis at the time of presentation $(4,5)$. About half of the patients who undergo resection of CRC will develop metastatic disease and $5-15 \%$ of those eventually develop lung metastases (6-8). For many years, the diagnosis of lung

\footnotetext{
*Correspondence to: Nedzhat Ali, Department of Special Surgery and Second Surgical Clinic, University Hospital "St. George", MU-Plovdiv, Bulgaria,drnedzhatali@gmail.com
}

metastasis was considered the end stage of the disease course. Surgical treatment of lung metastases has been given a boost in the last 15 years, as has been shown in the literature, and some of the major prognostic factors for this condition have been identified $(9,10)$. Pulmonary metastasectomy is associated with prolonged survival in selected patients. Reported median survival ranges from 35-50 months (11-16). 5-year survival rates after surgical resection range from $36-67.8 \%$. (11, $17,18)$

\section{PURPOSE}

The aim of our study was to analyze survival in patients operated on due to lung metastases from colorectal cancer.

\section{PATIENTS AND METHODS}

This was a retrospective study based on surgical records of the Clinic of Thoracic and Abdominal Surgery at the University Hospital „St. George“-Plovdiv, Bulgaria. We reviewed all records of complete resection of metastatic lung lesions performed in patients with a previous diagnosis of primary CRC between January 1, 2004 and November 20, 2013. Ten 
of the patients were male and 3 were female. The average age was 62.5 year. The youngest and oldest patients were respectively 39 and 71 years old and were men. The shortest survival period after surgery was 29 days and the longest - 81 months. The mean DFI was 26.6 months. The prevailing CT characteristics of the pulmonary metastases were rounded lesions with sharp outlines. Patients with one metastatic lesion were 9, those with two metastases were 2 and those with three or more than three lung lesions were also 2. Patients with lesions smaller than $20 \mathrm{~mm}$ were 4 and those with metastases bigger than $20 \mathrm{~mm}$ were 10. Thirteen thoracotomies and a single VATS were performed. One of the patients was operated on twice due to recurrent pulmonary metastasis. Five lobectomies and 9 atypical resections of lung parenchyma were performed.

\section{STATISTICS}

We analyzed our data using SPSS ${ }^{\circledR}-\mathrm{IBM}$ SPSS Statistics for Windows 19.0.0.and Microsoft巴 Office Excel. Descriptive methods and methods of assessment were used. The method of Kaplan-Meier was used for survival analysis.

\section{RESULTS AND DISCUSSION}

We found that the mean survival of patients operated on due to pulmonary metastases from CRC was 57.1 months (95\% CI; 35,40078,907). (Figure 1) The shortest survival period after surgery was 29 days and the longest - 81 months. Although CRC is referred to as a systemic disease and despite doubts about the effect of locoregional therapy in its management, many surgeons perform surgical resection of lung metastases in properly selected patients (19-24). In general, the presence of metastases portends a poor prognosis; however, according to some studies 5-year survival rate reaches 50\% (25). Inoue $\mathrm{M}$. conducted a retrospective study on 128 patients who had been operated on due to lung metastases from CRC and reported rates of 3- and 5-year survival of respectively $44,6 \%$ and 45,3\% (13). According to other studies 5year survival reaches up to $55.4 \%$ with median survival of 70.1 months (26). Some even report 5-year survival rate of $67.2 \%$ (27). Currently, although there are studies calling into question the positive effects of surgery in patients with pulmonary metastases from CRC (22), it remains a significant component of the treatment of lung metastatic disease, and its practice is widely accepted worldwide, resulting in low mortality rates and increased five-year survival rates (28-30).

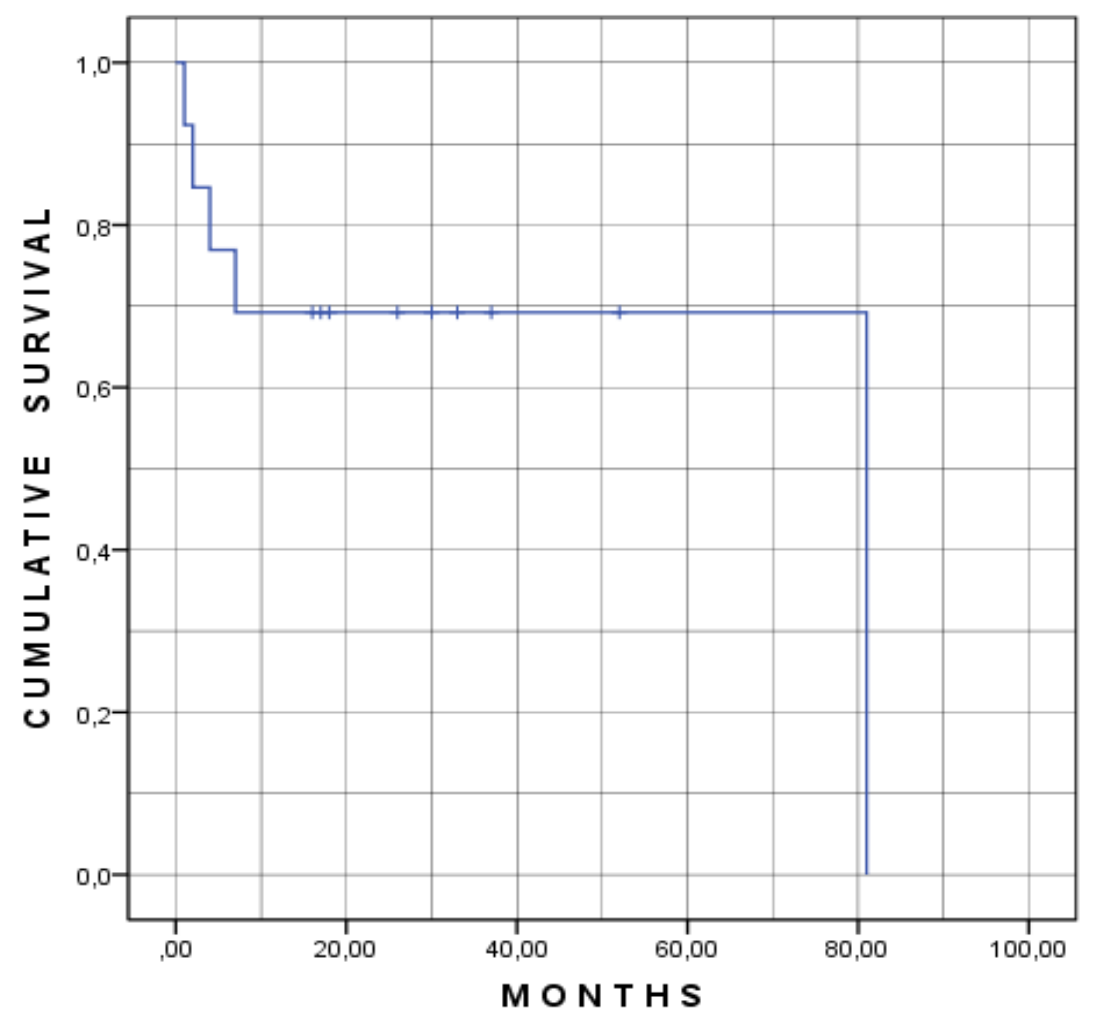

Figure 1. Survival in patients surgically treated on the occasion of pulmonary metastases from colorectal carcinoma 


\section{CONCLUSION}

We conclude that pulmonary resection of metastatic colorectal carcinoma is safe and results in long-term survival. Low morbidity and mortality rates, contrasting with lack of any other effective therapy, justify aggressive surgical management.

\section{REFERENCES}

1. International Agency for Search on Cancer, GLOBOCAN 2012: Estimated Cancer Incidence,Mortality and Prevalence Worldwide in 2012.

2. E. Yordanova, L. Petkova, M. Nedelkova, NATIONAL STATISTICAL INSTITUTE HEALTH 2014; "Demographic and Social Statistics", Department "Statistics of health and justice": ISSN 1313-1907.

3. E. Yordanova, L. Petkova, NATIONAL STATISTICAL INSTITUTE - HEALTH 2015; "Demographic and Social Statistics", Department "Statistics of health and justice": ISSN 1313-1907.

4. Villeneuve, P. James, and R. Sudhir Sundaresan, "Surgical Management of Colorectal Lung Metastasis." Clinics in Colon and Rectal Surgery 22.4: 233-241, 2009.

5. Jemal A, Siegel R, Ward E, Hao Y, Xu J, Murray T, et al. Cancer statistics, 2008. CA Cancer J Clin; 58:71-96, 2008.

6. Kim H. K, Cho J. H, Lee H. Y, Lee J, Kim J. Pulmonary metastasectomy for colorectal cancer: How many nodules, how many times? World J Gastroenterol ; 20 (20): 6133-6145, 2014, Available from: URL: $\quad$ http://www.wjgnet.com/10079327/full/v20/i20/6133.htm DOI: http://dx.doi.org/10.3748/wjg.v20.i20.6133

7. Bristerh S. J, de Varennes B, Gordon P. H, Sheiner N. M, Pym J. Contemporary operative management of pulmonary metastases of colorectal origin. Dis Colon Rectum. 1988; 31:786-92.

8. McCormack P. M, Burt M. E, Bains M. S, Martini N, Rusch V. W, Ginsberg R. J. Lung resection for colorectal metastases. 10-year results. Arch Surg.; 127:1403-6, 1992.

9. Fujisawa T, Yamaguchi Y, Saitoh Y, Sekine $\mathrm{Y}$, Iizasa $\mathrm{T}$, Mitsunaga $\mathrm{S}$, et al. Factors influencing survival following pulmonary resection for metastatic colorectal carcinoma. Tohoku J Exp Med;; 180(2):153-160, 1996 , http://dx.doi.org/10.1620/tjem.180.153 [PubMed]

10.Dellai R. C. A, Chojniak R, Marques E, Younes R. N. Detecção de nódulos pulmonares por tomografia
UCHIKOV A, et al.

computadorizada em pacientes com metástases pulmonares submetidos à cirurgia. J Pneumol.20 (Suppl 3): 28-28, 1994.

11. Saito Y, Omiya H, Kohno K, Kobayashi T, Itoi K, Teramachi M, et al. Pulmonary metastasectomy for 165 patients with colorectal carcinoma: a prognostic assessment. J Thorac Cardiovasc Surg; 124:1007-13, 2002.

12. Yedibela S, Klein $P$, Feuchter K, Hoffmann M, Meyer T, Papadopoulos T, et al. Surgical management of pulmonary metastases from colorectal cancer in 153 patients. Ann Surg Oncol; 13:1538-44, 2006.

13.Inoue $M$, Ohta $M$, Iuchi $K$, Matsumura A, Ideguchi K, Yasumitsu T, et al. Benefits of surgery for patients with pulmonary metastases from colorectal carcinoma. Ann Thorac Surg; 78:238-44, 2004.

14.Iwasaki A, Shirakusa T, Yamashita Y, Noritomi T, Maekawa T, Hamada T. Characteristic differences between patients who have undergone surgical treatment for lung metastasis or hepatic metastasis from colorectal cancer. Thorac Cardiovasc Surg; 53:358-64, 2005.

15. Meimarakis G, Spelsberg F, Angele M, et al. Resection of pulmonary metastases from colon and rectal cancer: factors to predict survival differ regarding to the origin of the primary tumor. Ann Surg Oncol; 21:2563-72, 2014.

16.Zampino M. G, Maisonneuve P, Ravenda P. S, et al. Lung metastases from colorectal cancer: analysis of prognostic factors in a single institution study. Ann Thorac Surg; 98: 1238-45, 2014.

17. Watanabe K, Nagai K, Kobayashi A, et al. Factors influencing survival after complete resection of pulmonary metastases from colorectal cancer. Br J Surg; 96:1058-65, 2009.

18. Mori $\mathrm{M}$, Tomoda $\mathrm{H}$, Ishida $\mathrm{T}$, et al. Surgical resection of pulmonary metastases from colorectal adenocarcinoma. Special reference to repeated pulmonary resections. Arch Surg; 126:1297-301, discussion 1302, 1991.

19.Long-term results of lung metastasectomy: prognostic analyses based on 5206 cases. The International Registry of Lung Metastases. J Thorac Cardiovasc Surg; 113:37-49, 1997. [PMID: 9011700 DOI: 10.1016/S0022-5223(97)70397-0]

20.Internullo E, Cassivi S. D., Van Raemdonck D, Friedel G, Treasure T. Pulmonary metastasectomy: a survey of current practice amongst members of the 
European Society of Thoracic Surgeons. $J$ Thorac Oncol; 3: 1257-1266, 2008. [PMID: $18978560 \quad$ DOI: 10.1097/JTO.0b013e31818bd9da]

21.Pfannschmidt J, Dienemann H, Hoffmann H. Surgical resection of pulmonary metastases from colorectal cancer: a systematic review of published series. Ann Thorac Surg; 84: 324-338, 2007. [PMID: 17588454

DOI: 10.1016/j.athoracsur.2007.02.093]

22.Fiorentino F, Hunt I, Teoh K, Treasure T, Utley M. Pulmonary metastasectomy in colorectal cancer: a systematic review and quantitative synthesis. $J$ R Soc Med; 103: 60-66, 2010. [PMID: 20118336 DOI: 10.1258/jrsm.2009.090299]

23.Salah S, Watanabe K, Welter S, Park J. S, Park J. W, Zabaleta J, Ardissone F, Kim J, Riquet M, Nojiri K, Gisabella M, Kim S. Y, Tanaka K, Al-Haj Ali B. Colorectal cancer pulmonary oligometastases: pooled analysis and construction of a clinical lung metastasectomy prognostic model. Ann Oncol; 23: 2649-2655, 2012. [PMID: 22547539 DOI: 10.1093/annonc/mds100]

24.Gonzalez M, Poncet A, Combescure C, Robert J, Ris H. B, Gervaz P. Risk factors for survival after lung metastasectomy in colorectal cancer patients: a systematic review and meta-analysis. Ann Surg Oncol; 20: 572-579, 2013. [PMID: 23104709 DOI: $10.1245 / \mathrm{s} 10434-012-2726-3$ ]

25.Zisis C, Kosmas Tsakiridis, Ioanna Kougioumtzi, Paul Zarogoulidis,Kaid Darwiche, Nikolaos Machairiotis, Bojan Zaric, Nikolaos Katsikogiannis, Georgios Kesisis, Aikaterini Stylianaki, Zhigang Li and Konstantinos Zarogoulidis, The management of the advanced colorectal cancer: management of the pulmonary metastases, $J$ horac Dis.; 5[Suppl 4].: S383-S388, 2013. doi:
UCHIKOV A, et al. 10.3978/j.issn.2072-1439.2013.06.23

PMCID: PMC3791498

26. Blackmon S. H, Stephens E. H, Correa A. M, Hofstetter W, Kim M. P, Mehran R. J, Rice D. C, Roth J. A, Swisher S. G, Walsh G. L, Vaporciyan A. A, Predictors of recurrent pulmonary metastases and survival after pulmonary metastasectomy for colorectal cancer; Ann Thorac Surg. Dec; 94[6].:1802-9, $2012 . \quad$ doi: 10.1016/j.athoracsur.2012.07.014. Epub 2012 Oct. 11.

27. Cho J. H, Hamaji M, Allen M. S, Cassivi S. D, Nichols F. C 3rd, Wigle D. A, Shen K. $\mathrm{R}$, Deschamps C, The prognosis of pulmonary metastasectomy depends on the location of the primary colorectal cancer; Ann Thorac Surg. Oct;98[4]. 2014: 1231-7. doi: $\quad$ 10.1016/j.athoracsur.2014.05.023. Epub 2014 Jul 31

28.Poletti, Giana Balestro et al. "Descriptive Analysis of and Overall Survival after Surgical Treatment of Lung Metastases." Jornal Brasileiro de Pneumologia: Publicaçäo Oficial da Sociedade Brasileira de Pneumologia e Tisilogia 39.6: 650-658, 2013 PMC. Web. 10 June 2016.

29.Pfannschmidt J, Muley T, Hoffmann H, Dienemann $\mathrm{H}$. Prognostic factors and survival after complete resection of pulmonary metastases from colorectal carcinoma: experiences in 167 patients. $J$ Thorac Cardiovasc Surg. 126(3):732-739, 2003. http://dx.doi.org/10.1016/S00225223(03)00587-7 [PubMed]

30.Rama N, Monteiro A, Bernardo J. E, Eugénio L, Antunes M. J. Lung metastases from colorectal cancer: surgical resection and prognostic factors. Eur J Cardiothorac Surg.; 35(3): 444-449, 2009. http://dx.doi.org/10.1016/j.ejcts.2008.10.04 7 [PubMed] 